\title{
Multiple Sklerozisde Biyotin Kullanımının Etkileri
}

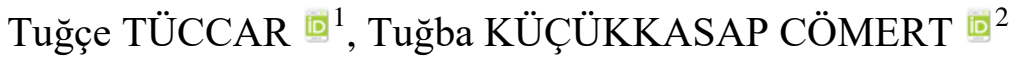

\begin{abstract}
ÖZ
Dünyada yaklaşık 2.5 milyon multiple sklerozis (MS) hastasının varlığına dikkat çekilmekte, MS 20. yüzyılın başlarından itibaren en sık görülen nörolojik hastalık olarak tanımlanmaktadır. Görülme sıklığı, Amerika Birleşik Devletleri ve Avrupa'da her 1000 genç yetişkin bireyde 1 olarak belirtilmektedir. Ülkemizde yürütülen epidemiyolojik çalışmalarda ise MS prevalansının 1000 genç yetişkin bireyde 0.4-1 olduğu gösterilmiştir. Görme bulanıklığı, diplopi, dizartri, konsantrasyon-dikkat bozukluğu, ekstremitelerde güçsüzlük, ataksi, yorgunluk, mesane sorunları sıklıkla rastlanan hastalık belirtileri olarak sıralanmaktadır. Patofizyolojisinde genetik ve çevresel risk etmenlerinin önemli rol oynadığı belirtilmesine rağmen MS için spesifik bir patogenez tanımlanmamıştır. Hızlı ilerleyebilen bir hastalık olması nedeniyle, tedavi seçenekleri üzerine çalşsmalar devam etmekte, ortaya çıkan olumsuz tablonun geciktirilmesi konusunda öneriler sunulmaktadır. Son yıllarda da biyotin konusuna dikkat çekilerek, bu konuda etkin bilgi ve deneyimin sağlanmasının, tedavi stratejilerinin gelişimine ışık tutacağı, hastalı̆̆ın ilerlemesini geciktirerek bireylerin yaşam kalitesinin geliş̧irebileceği önerilmektedir. Bu derlemede, yüksek doz biyotin kullanımın MS ile ilintili işlev bozuklarında iyileşme yolları konusunda ortaya konan hipotezler ve bu bağlantıda yapılan çalışma sonuçlarının değerlendirilmesi amaçlanmıştır.
\end{abstract}

Anahtar Kelimeler: Multiple sklerozis; biyotin; hastalık.

\section{The Effects of Biotin Use in Multiple Sclerosis}

\begin{abstract}
Multiple sclerosis (MS) is the most common neurological disorder since the beginning of the 20th century and approximately 2.5 million patients with MS are estimated in the world. It is reported that MS is seen 1 in one thousand young adults in the United States and Europe. The epidemiological studies conducted in our country show that the prevalence of MS is 0.4-1 per thousand. Visual blur, diplopia, dysarthria, concentration-attention disorders, weakness in extremities, ataxia, fatigue, bladder problems are frequently listed as symptoms. Although genetic and environmental risk factors play an important role in pathophysiology, there is no specific pathogenesis for MS. Due to the fact that it is a rapidly progressive disease, studies on treatment options are continuing and suggestions for delaying the symptoms are presented. In recent years, topics are highlight on the biotin issue, to delay the progression of the disease and to improve the quality of life of individuals. In this review, it is aimed to evaluate the hypotheses about the ways of improvement in MS related dysfunctions of high dose biotin use and the results of the study in these subjects.
\end{abstract}

Keywords: Multiple sclerosis; biotin; disease.

\section{GíRIŞ}

Multiple sklerozis (MS), nedeni kesin olarak bilinmeyen ve kesin tedavisi olmayan kronik bir hastalıktır. Merkezi sinir sisteminde (MSS); beyin sapı, perivenöz alanlar, optik sinir çevresi, serebellumun periventriküler beyaz maddesi başta olmak üzere birçok alanda plak gelişimi ifade edilmektedir. Bu plakların myelin içeren bölümlerde gelişerek, skar oluşturdukları bilinmektedir. MS'de myelin ve akson hasarına neden olan mekanizmanın otoimmun olaylar sonucu ortaya çıktığı önerilmekte, ancak bu otoimmun olayları başlatan süreç bilinmemektedir (1-3).

1 Yüksek İhtisas Üniversitesi, Sağlık Bilimleri Fakültesi, Beslenme ve Diyetetik Bölümü, Ankara, Türkiye

2 Sağlık Bilimleri Üniversitesi, Gülhane Sağlık Bilimleri Fakültesi, Beslenme ve Diyetetik Bölümü, Ankara, Türkiye

Sorumlu Yazar / Corresponding Author: Tuğba KÜÇÜKKASAP CÖMERT, e-mail: tugbaccomert@gmail.com

Geliş Tarihi / Received: 01.08.2018, Kabul Tarihi / Accepted: 14.12.2018 
MS oluşumunda sorumlu olan myelin proteinlerine yönelen hücresel yanıtın, $\mathrm{T}$ hücreleri tarafından oluşturulduğu önerilmekte, $\mathrm{T}$ lenfositlerin aktive olduğu ve kan beyin bariyerini geçerek MSS'ye ulaştı̆̆ 1 belirtilmektedir. $\mathrm{Bu}$ süreç sonunda da miyelin kılıf hasarının oluştuğu ifade edilmektedir $(3,4)$.

Hastalığın etiyolojisi net olarak bilinmemekle birlikte, patolojik otoimmunitenin hastalığın oluşmasında etkin olduğu ve otoimmüniteyi enfeksiyonlar, genetik ve çevresel etmenlerin etkilediği gösterilmektedir $(5,6)$.

MS'de spastisite, patolojik refleksler, hemiparezi, konuşma ve koordinasyon bozuklukları, idrar boşaltma sorunları, parestezi, uyuşukluk gibi belirti ve bulguların sıklıkla görüldüğü belirtilmektedir. Şikâyetlerin süresinin değişkenlik gösterdiğine dikkat çekilerek, yorgunluk, halsizlik gibi durumların gün içinde aralıklarla olabileceği gibi, günlerce ve haftalarca sürebildiği saptanmıştır $(5,7)$.

MS görülme sıklığı, kadın bireylerde erkeklere göre 1.5-2 kat daha fazla olduğu saptanmıştır. Genç erişkinlerde görülme riskinin, ileri yaşlardaki kişilerden daha fazla olduğu belirtilse de, ileri yaşın mortaliteyi artırdığına da dikkat çekilmiştir. Dünyada MS prevalansının, tropikal bölgelerde daha nadir olduğu ortaya konmuş, Kuzey Avrupa, Güney Kanada, İsrail, Kuzey Amerika, Yeni Zelenda ve Güney Avustralya'da görülme sıklığının yüksek olduğu belirtilmiştir $(8,9)$.

MS için, hastalığı tamamen iyileştirecek bir tedavi yönteminin olmadığ 1 hastalık seyrinin her bireyde farklı olabileceği bildirilmektedir. Akut belirtileri ortadan kaldırabilen, özürlülük gelişimine neden olan atakların sıklığını, süresini ve şiddetini azaltabilen ve atak sonrası ortaya çıkabilecek komplikasyonları iyileştirebilen tedaviler bulunmaktadır. Bu tedaviler üç temel başlıkta incelenmektedir; i) Akut atak tedavi, ii) Hastalığın doğal seyrinin değiştirmeye yönelik tedaviler ve iii) Semptomatik tedavi ile bireyin yaşam kalitesinin artırılması hedeflendiği ifade edilmektedir (10).

MS, bilinmeyen etiyolojisiyle kesin tedavi olmayan ve öngörülmez klinik seyri ile uyumu zor bir hastalık olarak tanımlanmaktadır. $\mathrm{Bu}$ nedenle hastalığın seyrini yavaşlatarak, özürlülükte azalmayı sağlayan, uyumu iyileştiren ve yaşam kalitesini artıran yeni tedavi seçenekleri konusunda arayışların devam ettiği bildirilmektedir (11) .

Son dönemde de, MS ile ilintili durumları iyileştirmede, yeni bir tedavi seçeneği olarak yüksek doz biyotin kullanımı konusunda hipotezler öne sürülmüş, bu konuda çalışmalar yapılmıştır. $\mathrm{Bu}$ derlemede de, bu konudaki çalışmalardan bahsedilerek, değerlendirilecektir.

\section{YÜKSEK DOZ BIYOTIN VE MULTIPLE SKLEROZIS \\ Yüksek Doz Biyotin ve Multiple Sklerozis}

Biyotin, vücudumuzda intestinal bakteriler tarafından sentezlenen, suda çözünen kompleks bir B vitamini olarak tanımlanmaktadır (12). Özellikle total parenteral beslenenlerde, kisa barsak sendromu ve emilim bozukluğu olan hastalarda eksikliğin görülebileceği bildirilmiştir (13). Amerika Ulusal Sağlık Enstitüsü'ne göre günlük yeterli alım düzeyi (adequate intake (AI)) 30 mcg olarak önerilmekte iken Türkiye Beslenme
Rehberi’ne (2015) göre 40 mcg/gün olarak belirtilmektedir $(14,15)$.

MS ve biyotin ile ilgili çalışmalar 1999'da Anagnostouli ve arkadaşlarının (16) serum ve beyin omurilik sıvısında (BOS) biyotin düzeylerini analiz etmesi ile başlamıştır. Yaptıkları araştırmada hem BOS, hem de serum biyotin düzeylerinin MS'li grupta, kontrol grubuna göre anlamlı derecede düşük olduğunu saptamışlardır. Bunun nedeni ise emilim bozuklukları intestinal flora tarafından yetersiz biyotin sentezi ve düşük biyotin bağlayıcı immunoglobulin (BBI) düzeyleri olduğu düşünülmektedir.

Sedel ve ark. (17) optik nöropati ve lökoensefalopatisi olan beş bireyin klinik olarak yüksek dozda biyotine yanıt verdiklerini belirlemişlerdir. Bu bireylerden birinin MS hastası olduğu tespit edilmiş, yüksek dozda biyotinin MS tedavisinde yararlı olabileceği rapor edilmiştir.

Majer-Janson ve arkadaşlarının (18) yaptığı bir çalışmada MS'li bireylerin serum biyotin düzeylerinin kontrol grubuna göre daha düşük olduğu kaydedilmiştir. Ayrıca serum biyotin düzeyinin 100-200 ng/L olması optimal düzeyin altında, $<100 \mathrm{mg} / \mathrm{l}$ olması ise biyotin desteğinin gerekli olduğunu göstermiştir. Düşük biyotin düzeyinin MS için bir risk etmeni olarak tanımlanabileceği ifade edilmiştir.

Oral olarak alınan biyotinin tamamen emildiği, metabolitlerinin ise idrarla atıldığı bilinmektedir. Yüksek dozda biyotinin de, kan-beyin bariyerinden taşınarak beyne ulaşması beklenmekte ve yapılan çalışmalarda, bu yol ile MS tedavisinde olumlu sonuçlar ortaya çıkarabileceği belirtilmektedir. Son yıllarda bu verilerden yola çıkılarak, MS'de yüksek doz biyotin tedavisinin olası olumlu etkilerini değerlendiren çalışmalar planlanmaya başlanmıştır. Yüksek doz biyotin (100-300 mg/gün) desteği, primer ve sekonder progresif MS'li 23 bireyde, 2-36 aylık süreçte (ort. 9.2 ay) değerlendirilmiş, optik sinir yaralanmasına bağlı belirgin görme bozukluğu olan dört bireyde görme keskinliğinin anlamlı derecede iyileştiği, iki bireyde ise görsel uyarılmış potansiyellerin ilerlediği saptanmıştır (19).

Çift kör, plasebo kontrollü yapılan bir çalışmada ise, 91 MS tanısı ile izlenen bireye 12 ay süre ile yüksek doz (100 mg x 3 / gün) biyotin desteği verilmiş ve $42 \mathrm{MS}$ 'li birey ise plasebo olarak izlenmiştir. Yüksek doz biyotin desteği alan gruptaki bireylerin \%12.6'sında işlev bozukluğu durumunun iyileştiği, plasebo grupta ise bu iyileşmenin olmadığı rapor edilmiştir $(p=0.005)$. Yüksek doz biyotin ile nöron veya oligodendrosit metabolizmasının hedeflenmesinin, progresif MS'li hastalar için etkili ve güvenli bir tedaviyi temsil edebileceği, ancak uzun dönemli, geniş örneklem sayısına sahip çalışmaların gerekliliği belirtilmiştir (20).

MS'li bireylerde yüksek doz biyotin kullanımın olumlu sonuçlarının yanı sıra, yapılan çalışmalarda tam tersi, farklı sonuçlara da dikkat çekilmektedir. Birnbaum ve ark. (21) progresif MS’li 43 bireyde, 300 mg/gün (tek kapsül) biyotin desteğini değerlendirdikleri çalışmada, yüksek doz biyotinin bireyler tarafindan tolere edilebildiğini saptamışlar, ancak hastaların üçte birinin (\%38-43) tedavi sırasında kötüleştiğini (alt ekstremite güçsüzlügüu, kötüleşen denge ve daha fazla düşme) ve biyotin alımı durdurduktan sonra durumun düzeldiğini göstermişlerdir. Tedavi sırasında kötüleşme nedeni 
hastalıkları ile ilişkilendirilmiş, ancak bazı bireylerde zarar görmüş merkezi sinir sisteminin biyotin tarafından uyarılarak artan metabolik taleplere yanıt verememesi nedeni ile olabileceğine dikkat çekilmiştir.

Hu ve ark. (22) yüksek doz (300 mg/gün) biyotin desteği alan MS'li kadın bireyde biyotin desteği sürecinde ve 3 günlük süreç sonrasında, tiroid stimüle edici hormon (TSH) ve tiroksin T4 düzeylerinin uyumsuz olduğunu göstermişler, buna karşın bireyde irritabilite, uyku zorluğu, taşikardi, sıcak basması, diyare veya vücut ağırlığı kaybı semptomlarına ise rastlanmadığını ifade etmişlerdir. Bireyin semptomları ile laboratuvar bulguları arasındaki bağlantının olmamasını olası psödohipertroidizm tanısı olarak önermişlerdir. $\mathrm{Hu}$ ve ark. (22) Amerika MS Araştırma ve Tedavi Komitesi panelinde sundukları olgu çalışmalarında, yüksek doz (300 mg/gün) biyotin desteği alan MS'li kadın bireyde biyotin desteği sürecinde ve 3 günlük süreç sonrasında, desteği verilen süreçte serum tiroid stimüle edici hormon (TSH) ve tiroksin T4 düzeylerinin sirası ile 0.032 $\mathrm{uIU} / \mathrm{mL}$ (referans 0.45-4.5 uIU/mL) ve $>7.77 \mathrm{ng} / \mathrm{dL}$ (referans $0.82-1.77 \mathrm{ng} / \mathrm{dL}$ ) olduğunu, biyotin desteği kesildikten 3 gün sonra ise bulguların, TSH $2.46 \mathrm{uIU} / \mathrm{mL}$ ve T4 $1.1 \mathrm{ng} / \mathrm{dL}$ olarak değiştiğini göstermişler, bireyde irritabilite, uyku zorluğu, taşikardi, sıcak basması, diyare veya vücut ağırlığı kaybı semptomlarına ise rastlanmadığını ifade etmişlerdir. Bireyin semptomları ile laboratuvar bulguları arasındaki bağlantının olmamasını olası psödohipertroidizm tanısı olarak önermişlerdir.

Benzer şekilde, 69 yaşında progresif MS tanısı ile izlenen kadın bireye 3x100 mg/gün biyotin desteği başlanmış, herhangi bir semptoma rastlanmaksızın tiroid işlev testlerinde bozukluk belirtilerek, tirotoksikoz ve Graves hastalığı gelişim riski olarak algılanabileceğine dikkat çekilmiştir (23).

Hayvanlar ile yapılan bir çalışmada, yüksek doz (30 $\mathrm{mg} / \mathrm{kg} /$ gün) biyotin verilen gebe tavşanların fetuslerinde teratojenik etkiler gösterilerek, MS'li kadın bireylerde mutlaka gebeliklerin planlı olması ve gebelik sürecinde biyotin desteğinin kesilmesi önerilmiştir. Yüksek doz biyotin desteği alan tavşanların fetusleri, kontrol grubu (15 $\mathrm{mg} / \mathrm{kg} / \mathrm{gün}$ biyotin) ile karşılaştırıldığında, \%11.8'inde kötü huylu pençe, \%4.1'inde kubbeli kafa, $\% 4.1$ 'inde hidrosefali ve \%4.7'sinde kranial kaviteda sıv1 saptandığı belirtilmiştir (24).

Yüksek dozda biyotinin, spinal progresif MS'li bazı bireylerde etkinlik gösterdiği, ancak latent inflamatuar durumu ortaya çıkarabileceğine dikkat çekilmektedir (23,25-27).

\section{PROGRESIF MS TEDAVISINDE YÜKSEK DOZ BIYOTIN İÇIN ORTAYA KONAN HİPOTEZLER Progresif MS Tedavisinde Yüksek Doz Biyotin İçin Ortaya Konan Hipotezler}

Biyotinin, biyotin bağımlı karboksilasyon tepkimelerinde taşıyıcı, yağ asidi sentezinde, dallı zincirli aminoasitlerin katabolizmasında ve glukoneojenik tepkimelerde görev alan karboksilaz enzimler (pürivatkarboksilaz (PC), 3metilkrotonil-coA karboksilaz (MCC), propionilcoA karboksilaz (PCC) ve asetilcoA karboksilaz için de elzem bir koenzim olduğu belirtilmektedir. Bazı mikroorganizmalarda, bu enzimlerin CO2 fiksasyonu, metanol, asetil-CoA ve 3-hidroksipropionat asimilasyonu, mikolik asit ve metil-dallı yağ asitleri biyosentezi, poliketid biyosentezi, terpenoidlerin metabolizmasında ve ürenin nitrojen kaynağı olarak kullanımında da önemli işlevlere sahip oldukları da gösterilmiştir $(12,13,28)$.

Progresif MS'te yüksek doz biyotinin, oligodendrositlerde myelin oluşumunu artırarak myelinizasyonu teşvik edeceği ve virtual hipoksiyi geriye döndürerek demyelinize aksonların dejenerasyondan koruyabileceği hipotezleri öne sürülmektedir (24).

Remyelinizasyonun desteklenmesi, progresif MS tedavisi için yararlı bir yöntem olarak gösterilmekte, yüksek doz biyotin myelin membran sentezini artırarak remyelizasyonu teşvik edebilmektedir $(24,29,30)$.

MS'de demyelinize liflerin enerji gereksiniminin artırmasının yanı sıra, mitokondriyal hasar nedeni ile enerji oluşum sürecinin de sorun olabildiği belirtilmekte ve "virtual hipoksi" olarak tanımlanmakta, demyelinize aksonların dejenerasyondan korunmasında yüksek doz biyotin aracılığı ile iyileştirme sağlanarak tedavide etkin sonuçların ortaya çıkabileceğine dikkat çekilmektedir (17-19). Karboksilaz enzimleri için (PC, MCC ve PCC) kofaktör olan biyotinin, kreps döngüsünde ATP oluşumunu artırabileceği ve böylece virtual hipoksi durumunu tersine çevirebileceği düşünülmektedir (24).

\section{SONUÇ VE ÖNERILER}

Progresif MS'de yüksek doz biyotinin potansiyel etki mekanizması tam olarak belirlenememiş, ön klinik verilerin yetersizliğinin olduğu gösterilmiştir. Yüksek doz biyotin desteğinin güvenilir ve etkinliğini değerlendiren uzun dönemli, geniş örneklem sayısına sahip çalışmalara gereksinim olduğu belirtilmektedir (24).

Özellikle fingolimod tedavisi alan MS'li bireylerde, kardiyovasküler komplikasyonlar, enfeksiyon, maküler ödem gibi risk etmenleri nedeni ile bu bireylerde yüksek doz biyotin desteğinin sik klinik izlem ile birlikte planlanması önerilmektedir (31).

Ayrıca Besin İlaç Dairesi (FDA), yüksek doz biyotin kullanımının yanıltıcı laboratuvar sonuçlarına neden olabildiğini ifade ederek, bu doğrultuda yanlış tedavi uygulanması sonucu kendilerine bir ölüm olgusu rapor edildiğine dikkat çekmektedir. Saç, deri ve tırnak sağlığ için kullanılan ürünlerde biyotin içerdiğinin altı çizilerek, klinisyenlerin yüksek doz planlamalarında tüm bunlara dikkat etmeleri gerektiği belirtilmiştir (32).

MS'de immunomodülatör tedavilerin hastalığın doğal seyrini değiştirmeyi hedeflemekte, kısmen başarılı olarak tanımlanmaktadırlar. Semptomlara yönelik tedavilerin ise hastaların günlük yaşamında kaliteyi artırmaya yönelik olduğu bildirilmekte, immunomodülatör tedavinin önüne geçebildiğine dikkat çekilmektedir. $\mathrm{Bu}$ nedenle, genel öneriler yerine, bireye özgü yaklaşımın elzem olduğu, standart ve herkese uygulanabilir tek tip uygulamaların olamayacağı akılda tutulmalı, genel olarak yüksek doz biyotinin hangi semptomlarda durumu iyileştirmede veya ilerlemesini engellemede etkin olabileceği net olarak ortaya konularak, bireye özgü olduğu vurgulanmalıdır.

\section{KAYNAKLAR}

1. Tavşanlı M, Altıntaş A. Multipl Skleroz Patogenezi ve Yenilikler. Klinik Gelişim. 2012; 10(1); 61-4.

2. Giannetti P, Politis M, Su P, Turkheimer F, Malik O, Keihaninejad S, et al. Microglia activation in multiple 
sclerosis black holes predicts outcome in progressive patients: An in vivo [(11)C](R)-PK11195-PET pilot study. Neurobiol Dis. 2014; 65:203-10.

3. Alan JT, Sergio EB, Jeroen G, Bernhard H, Olga C. Multiple sclerosis. The Lancet. 2018; 391(10130): 1622-30.

4. Ciccarelli O, Toosy A. Neurological Rehabilitation of Multiple Sclerosis. In: Thompson AJ, editor. Neurological Rehabilitation of Multiple Sclerosis; 2006. p. 1-29.

5. Compston A, Coles A. Multiple sclerosis. Lancet. 2008; 372(9648): 1502-17.

6. Marrie RA. Environmental risk factors in multiple sclerosis etiology. The Lancet Neurology. 2004; 3(12): 709-18.

7. Tataru N, Vildal C, Decavel P, Berger E, Rumbach L. Limited impact of the summer heat wave in France (2003) on hospital admissions and relapses for multiple sclerosis. Neuroepidemiology. 2006; 27(1): 28-32.

8. Ünal Akdemir N. Multiple skleroz'un Orta Karadeniz bölgesindeki prevalansı ve hastaların demografik özellikleri [Uzmanlık Tezi]. Samsun: Ondokuz Mayıs Üniversitesi Tıp Fakültesi; 2011.

9. Tülek Z. Multipl sklerozlu hastanın hemşirelik bakımı. C.Ü. Hemşirelik Yüksekokulu Dergisi. 2007; 11(2): 25-32.

10. Durelli L, Clerico M. The importance of maintaining effective therapy in multiple sclerosis. J Neurol. 2005; 252(3): 38-43.

11. Stepleman LM, Jumb R, Shelton SF, Hughes MD. Psychological Consultation services at a Multiple Sclerosis Clinic. Internal Journal of MS Care. 2009; 11(4): 180-6.

12. cot.food.gov.uk [Internet]. Expert Group on Vitamins and Minerals [Updated: 2003 May; Cited: 2018 December 6]. Available from: https://cot.food.gov.uk/sites/default/files/vitmin2003. pdf.

13. fao.org [Internet]. FAO/WHO Expert Consultation. Rome, Italy; 2001 [Cited: 2018 December 6]. Available from: http://www.fao.org/3/a-y2809e.pdf.

14. Otten JJ, Hellwig JP, Meyers LD. nap.edu [Internet]. United States of America; 2006 [Cited: 2018 December 6]. Available from: https://www.nap.edu/read/11537/chapter/1\#iv.

15. Pekcan G, Şanlıer N, Baş M. dosyasb.saglik.gov.tr [Internet]. Ankara, Türkiye; 2016 [Erişim tarihi: 6 Aralık 2018]. Erişim adresi: https://dosyasb.saglik.gov.tr/Eklenti/10915,tuberturkiye-beslenme-rehberipdf.pdf.

16. Türkiye Beslenme Rehberi 2015. Ankara: T.C. Sağlık Bakanlığı; 2016.

17. Anagnostouli M, Livaniou E, Nyalala JO, Evangelatos G, Zournas C, Ithakissios DS, et al. Cerebrospinal fluid levels of biotin in various neurological disorders. Acra Neurol Scand. 1999; 99(6): 387-92.

18. Sedel F, Challe G, Vignal C, Assouad R, Bellanger A, Galanaud D. A novel biotin sensitive leukodystrophy. J Inherit Metab Dis. 2011; 34: S267.
19. Maier-Janson W, Roth G, Scholz E. Biotin-deficiency and lower biotin ranges in MS patients- where is the connection? J Neurol Sci. 2017; 381(1): 782-6.

20. Sedel F, Papeix C, Bellanger A, Touitou V, LebrunFrenay C, Galanaud D, et al. High doses of biotin in chronic progressive multiple sclerosis: A pilot study. Mult Scler Relat Disord. 2015; 4(2): 159-69.

21. Tourbah A, Lebrun-Frenay C, Edan G, Clanet M, Papeix C, Vukusic S, et al. MD1003 (high-dose biotin) for the treatment of progressive multiple sclerosis: A randomised, double-blind, placebocontrolled study. Mult Scler. 2016; 22(13): 1719-31.

22. Birnbaum G, Stulc J. High dose biotin as treatment for progressive multiple sclerosis. Mult Scler Relat Disord. 2017; 18: 141-3.

23. Hu NN, Shin RK, Tornatore C. Pseudohyperthyroidism in a multiple sclerosis patient highdose biotin. ACTRIMS Forum; 2018 Feb 1-3; San Diego. Abstract P075.

24. Cusini C, Sassi L, De Paola G, Piantanida E. Apparent biochemical thyrotoxicosis due to assay interference by high-dose biotin given for multiple sclerosis. J Endocrinol Invest. 2017; 40(8): 889-90.

25. Sedel F, Bernard D, Mock DM, Tourbah A. Targeting demyelination and virtual hypoxia with high-dose biotin as a treatment for progressive multiple sclerosis. Neuropharmacology. 2016; 110(Pt B): 64453.

26. Lebrun C, Cohen M, Mondot L, Ayrignac X, Labauge P. A Case Report of Solitary Sclerosis: This is Really Multiple Sclerosis. Neurol Ther. 2017; 6(2): 259-63.

27. Al-Salameh A, Becquemont L, Brailly-Tabard S, Aubourg P, Chanson P. A somewhat bizarre Case of Graves Disease due to vitamin treatment. J Endocr Soc. 2017; 1(5): 431-5.

28. De Roeck Y, Philipse E, Twickler TB, VanGaal L. Misdiagnosis of Graves' hyperthyroidism due to therapeutic biotin intervention. Acta Clin Belg. 2018; 73(5): 372-6.

29. Tong L. Structure and function of biotin-dependent carboxylases. Cell Mol Life Sci. 2013; 70(5): 863-91.

30. Rakel D. Integrative Medicine. In: Jacobs B, editor. Multiple Sclerosis. Philadelphia: Elsevier. Fourth edition; 2018. p. 133-42.

31. Heidker RM, Emerson RM, LeVine SM. Metabolic pathways as possible therapeutic targets for progressive multiple sclerosis. Neural Regeneration Research. 2017; 12(8): 1262-7.

32. Fiume MZ. Final report on the safety assessment of biotin. Int J Toxicol. 2001; 20(4): 1-12. 